\title{
Taboo and Non-conventional Content as Attitude and Emotion Sensitive Tool
}

\author{
Yuliya Asotska \\ Tischner University, Cracow, Poland \\ Email: julia_asotska@yahoo.com.au \\ Agnieszka Strzałka \\ Pedagogical University, Cracow, Poland \\ Email: astrzalka27@gmail.com
}

\begin{abstract}
Affect in language learning, understood as an emotional reaction to the subject, learning environment, methods and contents, shows among learners at all levels of advancement and of all age groups. Positive affect, such as a feeling of interest, pleasantness (or usefulness) of tasks and satisfaction with one's performance, results in increased motivation to learn the language, while negative emotions, such as boredom, tension or fear, typically lead to negative attitudes and, as a consequence, low results of learning. As some learners, especially adult ones, tend to conceal their emotional reactions to the learning situation, not always may language teachers recognize the sources of the difficulties they experience. It has been an interest of the authors to study young adults" affective response to an alternative to typical ELT content, which is "safe", "universal", "politically correct" material, in the form of "sensitive", "nonconventional" or even "taboo" topics. Classroom research conducted in an institution of higher education showed increased interest, higher task motivation and active involvement on the part of the students with many years of English learning experience (sometimes fed up with same or similar content) whose teachers decided to use some "off record" themes to practice language skills in their classrooms.
\end{abstract}

Index Terms - taboo topics, non-conventional topics, speaking, emotions in learning process, humanistic approaches, motivation

\section{THEORETICAL ASSUMPTIONS}

\section{A. The Role of Student's Attitude to the Learning Situation}

Affect in language learning, understood as an emotional reaction to the subject, learning environment, methods and contents, shows among learners at all levels of advancement and of all age groups. As we know from Kraschen, negative attitude can successfully block learning and it is "acquirers with low affective filter [who] seek and receive more input, interact with confidence, and are more receptive to input they receive" (Richards and Rogers, 2001, p. 183). More recently, Schuman (1999, p. 32) argues, on the basis of "motivation studies, diary studies (Bailley, 1991, Bailey and Ochsner, 1983), and autobiographies (Schuman, 1997) of second language learners, that positive appraisals of the language learning situation (the target language, its speakers and the culture in which it is used, the teacher, the syllabus and the text), (...) enhance language learning and negative appraisals inhibit second language learning".

In this article we would like to focus our attention on the students' appraisal of the materials used in their English lessons, most specifically the topics used for practicing the speaking skill in the classroom.

\section{B. The Role of Emotions in Learning}

Emotions as an important element of the process of learning have been stressed by humanistic psychology, which directed our attention to the fact that learners' feeling, not just thinking, is important in the process of learning. Positive affect, such as a feeling of interest, pleasantness (or usefulness) of tasks and satisfaction with one's performance, results in increased motivation to learn the language, while negative emotions, such as boredom, tension or fear, typically lead to negative attitudes and, as a consequence, low results of learning.

It seems equally important for teachers to avoid raising negative emotions in their students, such as fear, apprehension, anxiety, (Oxford, 1999), help reduce the negative affect brought to the class as a result of previous experience, where low-self-esteem can be an example (de Andres, 1999), and seed some positive emotions, which will simply facilitate the learning process (Moskowitz, 1999). We can, of course, rely on the cognitive more - provide clear goals and structure, explain well and give opportunities for practice, thus teaching impeccably but in the "cold" way. Or, we can enter the hot path, where more emotional involvement on both sides will be necessary, where both hemispheres of the brain will be employed to work hard, thus helping each other for better results.

It has been the belief of the authors that students' emotional involvement in the lessons we teach does make a difference. Prior to the research described below we observed that the routine of language learning in formal 
circumstances often makes students, except for some highly motivated ones, passive, shy and day-dreaming. As a teacher educator, one of the Authors often heard in-service teachers complain that students are unmotivated, uncooperative, and simply look bored.

\section{TABOO AND NON-CONVENTIONAL CONTENT: PRACTICAL CONSIDERATIONS}

One way in which emotions can appear in the classroom is by the choice of topic for conversation, or, more globally, the content of the language teaching materials. Conventionally, topics used as language learning vehicles should refer to the students' everyday life experiences, so that personalization is possible, should foster world knowledge and help relate language material to real life. The question arises, to what extent current coursebook topics allow these goals? Thornbury, for example, is rather critical of that kind of content: the coursebooks avoid topics which might stir the students, such as the war, sex, politics while it is these topics that "trigger some lively and language-productive discussions" (Thornbury, 2002, p. 1). He is an ardent supporter of letting the learners "subvert the curriculum by seizing control of the discourse agenda" (ibid) letting them participate in the choice of topics that will appear in the foreign language classroom. Furthermore, it is a well-known issue that in the coursebooks, the topics that are given are quite conventional; the teacher, however, does not have to take the speaking topics only from the coursebook. "One of the best ways to motivate students and encourage them to speak is to ask them which topics they want to speak about. (...) A controversial topic can be an excellent motivation for students to become really involved in a discussion and communicate fluently in English" (Baker and Westrup, 2003, p. 93).

\section{A. The Coursebook Writer Perspective}

With all due respect to coursebook writers, who do their best to fill in coursebook pages with "up-to date content" "global issues" "involving tasks" (descriptions often found on coursebooks' back cover), we may observe a limited number of issues appearing in a still growing number of coursebooks available for any age group. As for the character of the typical coursebook content, Rinvolucri (1999) identifies a bland and unengaging "EFL sub-culture" as represented in "the soft, fudgey, sub-journalistic, woman's magaziney world of EFLese course materials" (Thornbury, 2002, p. 2).

Do coursebook writers take affect into consideration? Paradoxically, they do, safe topics are unlikely to insult anybody, offend the students or confuse the teacher. How deeply does, conventional coursebook material, however, go into the students' minds and hearts?

\section{B. The Students' Perspective}

How many times, as a language learner have you been asked questions like, Ok,.... Do you like cooking? What is your favourite sport? What are your holiday plans? or Where did you go on holiday last year? Talking about the same things all over again sounds boring, especially if you do not really enjoy the topic at all. Classroom interactions are by definition artificial and serve the purpose of practicing language skills. Students who are adult enough to accept it just tolerate the fact, assuming that its language not content that is important, or that it just has to be this way. But what about affect? How do the students react emotionally to this state of affairs? Are they ever asked what topics they would really liked to talk about in the foreign language? Van Lier (2001) cites evidence that "intrinsic motivation is closely related to the perception of being able to choose and of being somehow in control of one's actions. Actions that are perceived as being externally controlled [on the other hand] have a tendency to reduce intrinsic motivation" (Thornbury, 2002, p. 2). Thornbury adds "It follows that topics that are "externally controlled" will have a similar de-motivating tendency" (ibid). It is our hypothesis, that given the choice, students would go for topics other than those perennially suggested by typical pedagogically - prepared materials.

\section{The Teachers' Perspective}

With all the ideas of using authentic materials and putting students in the center that teacher hear during their teacher training, it is consistently difficult for teachers to do everything themselves. Teachers definitely appreciate the fact that more and more up-to date materials are offered to them by publishers and simply teach from coursebooks prepared for a given age group. Thornbury (after Johnson) warns again: "Teachers must be aware that commercial materials possess no scientifically or technologically proven powers to teach second languages; more importantly, teachers must look critically at commercial materials to determine their appropriateness for a particular group of students" (ibid, 3).

Recent publications, such as "Teaching unplugged" (Meddings and Thornbury, 2009) appeal to language teachers to adopt a "materials light approach", in which they consider the students needs and abilities first of all and give up ("unplug") teaching from the coursebook at least from time to time. In our project we take a different route, we do prepare materials, which are quite different form the usual everyday ELT content and let the students get engaged in it. If our hypothesis of the positive impact of taboo and non-conventional topics proves true, we would hope for teachers who do not normally risk using them to search for something similar in character, which suits their students best.

\section{THE PROJECT}

\section{A. Research Project Design}


The present study was designed to examine whether students at the FCE, advanced or proficiency levels of English would benefit from discussions on topics which normally cannot be found in their coursebook, based on authentic rather than pedagogical materials and the students' choice. The authors were thus evaluating a priori hypotheses, that taboo and non-conventional topics might work as an attitude and emotion sensitive tool.

The author prepared two lessons: "A kiss is just a kiss" - a taboo lesson and "Adoption" - a non-conventional lesson (see appendix for lesson outlines) and instructed four teachers to conduct them in their classes, to which they expressed their consent. The Authors differentiate between the two following terms: taboo and non-conventional lessons: it is assumed that the taboo topic is something that is unusual to talk about, but at the same time consists of some 'taboo'/shocking parts (e.g. talking about 'sex,' 'kissing'). The non-conventional lesson, on the other hand, concerns mostly speaking topics that are rather uncommon for discussion lessons in the class (e.g. talking about 'business,' in general English classes, or 'smiling').

The research project was initiated in 2009 and took place at Tischner European University in Cracow, Poland. The sampling of the subjects was done on a convenience mode. The group of 85 students took part in the project. All of them had studied English in their schools before coming to Tischner University and all of them studied English with Tischner's tutors for more than one semester.

\section{B. The Tools that We Have Used}

Three different surveys were prepared in order to document the study. First we intended to obtain preliminary information on how taboo and non-conventional topics might 'work' during speaking activities, so the pre-intervention survey was to check how important the speaking skill was for students and to recognise the student's attitude towards the discussion topics offered by the coursebook they have worked with. We also wanted to know if the teachers they have had prepared any taboo or non-conventional lessons, or modified coursebook discussion topics in order to make them more interesting for the students. Finally, the role of the first survey was to check which taboo or nonconventional topics might potentially be of interest to our students.

The other two surveys were applied post-interventionally, after each of the taboo and non-conventional topic lessons. The purpose of these two surveys were to find out the attitudes students had and the emotions they experienced in connection with the introduction of this type of content.

\section{Results}

Pre-intervention survey: students' view on speaking topics and activities

According to the results of the first survey, speaking practice was very important for our students. Almost all of the students agreed that this skill was crucial in learning and practising a foreign language.

Having the coursebook seemed important for our students, although some of them were in a quandary and could not decide whether the coursebook is important for them or not. When the students were asked if the topics in the coursebooks motivate them to speak, the reply was rather - "no, the speaking topics do not motivate us to speak" (49\% of students marked the option 'no' and $29 \%$ of students marked the option 'neither agree nor disagree'). Only a small number of students $(22 \%)$ declared that the topics found in their books are interesting. Despite the fact that the students admitted that they like to study from the coursebook, still almost ninety percent of them stated that they want the teacher to give them some additional speaking topics to those that can be found in the book, or at least to adapt some of the speaking topics to their interests and needs. 


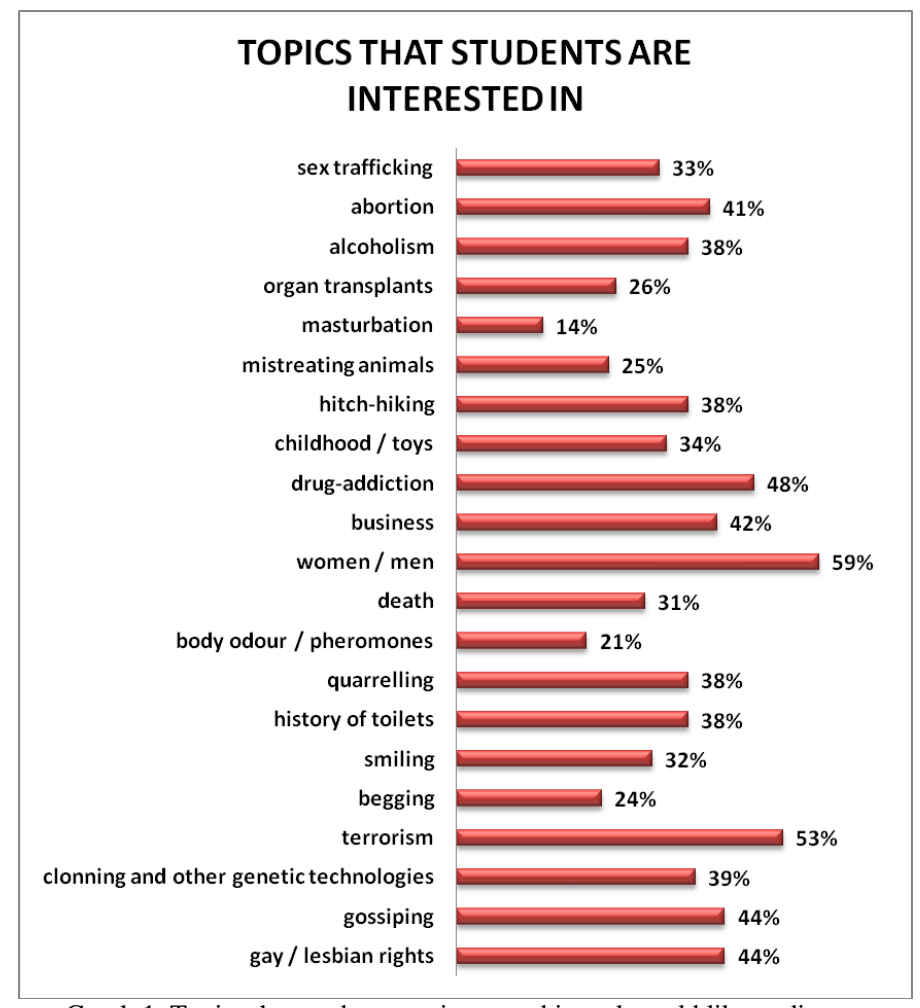

Graph 1. Topics that students are interested in and would like to discuss

The students were given a list of taboo and non-conventional topics (Graph 1). The topics on the list the authors invented by themselves or took ideas from Freeman's book. When it comes to the results students' responses disclosed that all the given topics are more or less desired type of content. The topics such as 'women / men', 'terrorism' and others are of interest for the vast majority of participants. However, the smallest percentage of students ticked topics, such as: 'body odour/pheromones' $-21 \%$, and 'masturbation' $-14 \%$ of students. This can be connected with the Polish attitude to taboo topics and our conservatism. Talking about masturbation in the class can be a way too shocking for the Polish mentality.

When students were asked why they would like to talk about all the topics from the list (Graph 1), we got the following answers: because they are "up-to-date and they are important in our everyday life". Some of the students claimed that they already know everything about the topics that they have covered from their coursebooks, however, they want to listen to others' opinions on the 'difficult' topics and they would like to learn new vocabulary connected with the unusual topics. At the same time, $67 \%$ of participants wrote that taboo and non-conventional topics are "interesting to talk about as there are many aspects to discuss"; "they are funny" and even "may cause quarrelling between the students", which need not be a negative feature in the class as long as it is properly managed. We know well that when students quarrel and try to prove their point, the speaking task engages them and creates a real life situation in the classroom.

Post intervention surveys: attitudes to non-conventional and taboo content

The second and the third surveys were applied after the two lessons, one based on a taboo and another on a nonconventional topic.

'A Kiss is just a Kiss'. The topic of kissing is not a very common topic covered in the class, probably that is why $95 \%$ of students liked this lesson, while $76 \%$ of all participants would like to have such lesson once again in the future. This lesson aroused only positive feelings in our students; most of the students claimed they felt "relaxed", "comfortable with the topic" and simply "good". The great majority of participants stated that they "wanted to laugh" and that they "wanted to speak", which was crucial. Sixty four percent of students wrote that the topic was interesting and that they wanted to talk to others and get to know their opinion. Only one percent of students wrote that "the topic was boring" and two percent claimed that they "did not feel comfortable with the topic". However, it must be noted here that four percent of the students who said they had not spoken in the lesson explained it with the fact that "many other students were talking" and they "did not get the chance for their opinion". The positive and pleasant atmosphere that was influenced by the topic made the students feel comfortable and, confident; they wanted to speak and to share their opinion with others.

'Adoption'. As in the case of the previous lesson, the lesson about adoption was also enjoyed by a large number of students. Only a small minority of students (9\%) did not like the lesson and felt uncomfortable with this topic. By and large, all the participants felt good, relaxed and comfortable with the topic. Seventy eight percent of students wanted to speak not only because this was a new topic but also because they found the topic interesting. Also, it must be noted 
that in this lesson not everyone wanted to laugh, which is understandable, as the topic of adoption is sad and tragic in some way. Despite the fact that this topic is difficult to talk about and perhaps personal, as some of students have noted, still $65 \%$ of students want to cover this topic once again in the future because they found it "unusual", "important" and the activities "interesting."

\section{CONCLUSION}

\section{A. How does the Attitude of Students Change?}

The majority of the respondents said before the intervention that they had talked about the same topics over and over again. When our learners become more and more proficient in English, they want to practise the new acquired vocabulary, grammar structures; however, the topics from the coursebook do not give them total freedom in what they want to say - "I don't want to speak about the topics that I have been doing all the time for the last ten years", said one of the students. Without doubt the topics that are given in the coursebooks are essential for our learners, however, as Klinger (1999) observes, "learners are curious about want to learn about and want to talk about events and items not only in their immediate social sphere and personal lives" (Porcaro, 2004, p. 39). They are interested in more profound topics, topics that relate to larger issues, for example, birth, death, good, evil, etc (Porcaro, 2004).

The research showed us that when we introduce 'unusual' topics into the classroom our students become more active; they want to participate in conversation and not only share their opinions but also listen to others. Students got a chance to speak on topics not only "seldom used" but "really interesting", "connected with society and our daily life", "funny, strange and similar to the topics you discuss with your friends", which they appreciated. Another thing mentioned was that "they gave a chance to practice very useful vocabulary".

\section{B. What Happens to Emotions?}

First off all, they appear openly in the classroom. Almost everyone is moved, interested by the very fact of something new and out-of-ordinary in the language classroom. Finally, something to talk about. The difference between talking in the language classrooms and talking in real life is that we in the former we mainly answer the questions asked by the teacher, seldom ask them ourselves, and we discuss "hot" topics which the course book has suggested for the day, often because it matched the grammar/vocabulary plan. So normally, we can say students stay emotionally uninvolved.

As Freeman (2003, p. 3) says, taboo and non-conventional topics "stir up controversy and impassioned feelings", when students feel that they have something new to say, they automatically become confident, relaxed, and they feel a desire to talk with their friends. This changes the classroom atmosphere towards a more natural way of communication, as if the learners were speaking outside the pressures of the classroom.

On the basis of the data obtained in this research project it can be observed that taboo or non-conventional topics for speaking do encourage students to speak. In particular, they arouse positive feelings in our students and make them interested in the lesson. Obviously, not all unusual topics make learners' feel good. As the research shows, the more serious the topic that is introduced (as in the example of Adoption), the more tension our students feel. The feeling of tension, however, does not appear in the negative sense here, it makes students show their real emotions and to share their real experience with others in a natural way.

Non-conventional and taboo topics seem to be linked with our students' willingness to speak and actively participate in the lesson. Advanced language learners, normally flooded with 'safe' speaking topics from the coursebooks who participated in the study appreciated the non-conventional and taboo content. The following quotations of students: "In my opinion these topics are more interesting than "normal” ones. I would really love to join discussion about drugaddiction or something because it would improve my language, etc." and "They are unusual topics that we don't use during the lesson. They are much more interesting and connected with society and our daily life" show that students are eager to discuss topics from everyday life, topics which they hear in the news and that are mentioned by their colleagues.

Hot topics in the classroom arouse positive attitude and generate positive emotions, even shy, not talkative students want to prove their opinion which trigger fruitful discussions during lessons. Students feel relaxed, they want to laugh, to be audible by others, etc. All these aroused emotions make our lessons enjoyable and unforgettable.

To conclude, topics such as, 'sex', 'torture', 'organ transplants', 'politicians', etc. are without doubt "hot topics". People see and hear different stories about them daily on the front pages of our newspapers, magazines, and television newscasts. These serious topics, "with so many angles to consider and viewpoints to integrate, are of special interest to our learners as they learn to live in a world that is very often filled with contradictions" (Freeman, 2005:vii). It is an indisputable fact that if we want to help our learners to use their second language freely, with meaning and interest, the presentation of non-conventional or taboo topics can be highly productive as they often generate high levels of interest and involvement in the learners.

\section{APPENDIX}

\section{'A KISS IS JUST A KISS'}

The first activity used was to make students guess the topic. Students were given five quotations that were told by well known people and they had to guess which key word goes to each of these sentences. Of course, the key word was 
'a kiss'. When students guessed the main topic, on the interactive board they saw many pictures of kissing (e.g. a kiss from the cartoon, a kiss of a mother and a child, a kiss between animals) and they had to think which picture was the best to choose for the post campaign in 'Kissing Festival', later there came the discussion why the chosen pictures were the best. In the third activity the students were given the survey 'Kissing Quiz' which checks their knowledge of the topic. After the survey the teacher divided students into two groups. After the division, the teacher gave each group questions and asked them to discuss these questions, in the end students and the teacher discussed these questions together. The title of another exercise was 'How to kiss Passionately'. Students were given cards with the steps of how to kiss someone passionately. While watching a taboo video students had to rearrange these cards in the correct order.

'ADOPTION'

For the beginning the teacher asked students to write down all of the different words they associated with the word ADOPTION. Next, students shared their words with their partner and talked about them. As the next step, students were divided into groups and given cards with questions about adoption which they discussed. In the third exercise students were shown pictures of famous people (like Madonna, Nicole Kidman, Angelina Jolie, etc.) and they discussed questions connected with the life of those famous stars. The last exercise was a role-play. Students worked in groups of threes and they had to play their role (a pop-star who wants to adopt a child; a boss of an African orphanage; a child in an African orphanage).

\section{REFERENCES}

[1] Baker, J. and Westrup, H. (2003). Essential speaking skills. Voluntary Service Overseas.

[2] De Andres, V. (1999). Self-esteem in the classroom or the metamorphosis of butterflies. In Affect in language learning. Ed. J. Arnold, 28-42. Cambridge: Cambridge University Press

[3] Freeman, S. (2003). Teaching hot topics. Jewish values, resources and activities. Colorado: A.R.E. Publishing, Inc

[4] Freeman, S. (2005). Hot topics. A student companion. New Jersey: A.R.E. Publishing, Inc

[5] Klinger, W. (1999). Unrehearsed speaking activities for language learning. Academic Reports of the University Center For Intercultural Education, The University of Shiga Prefecture, 4. Retrieved June 4, 2004, from http://www2.ice.usp.ac.jp/wklinger/QA/articles/kiyou99/k99speak.html

[6] Meddings, L. S. Thornbury. (2009). Teaching Unplugged. Delta Publishing.

[7] Moskowitz, G. (1999). Enhancing personal development: humanistic activities at work. In Affect in language learning. Ed. J. Arnold, 177-193. Cambridge: Cambridge University Press

[8] Oxford, R.L. (1999). Anxiety and the language learner: new insights. In Affect in language learning. Ed. J. Arnold, 58-67. Cambridge: Cambridge University Press

[9] Porcaro, J.W. (2004). Non-Conventional Content in English Language Lessons: "Death" as an Instructional Unit Application. TESL Reporter 37, 2, 39-49.

[10] Richards, J. C., and T. S. Rodgers. (2001). Approaches and methods in language teaching. 2nd ed. Cambridge: Cambridge University Press

[11] Schuman, J.H. (1999). A neurobiological perspective on affect and methodology in second language learning. Affect in language learning. Ed. J. Arnold, 28-42. Cambridge: Cambridge University Press

[12] Thornbury, S. (2002). Don't mention the war! Taboo topics and the alternative textbook. It's for Teachers 3: 35-37

Yuliya Asotska is currently doing a PhD in linguistic and methodology at Pedagogical University in Cracow. In 2009 she wrote her MA thesis in methodology of foreign language teaching at Pedagogical University in Cracow. She has taught English courses for the last four years at Tischner University in Cracow.

Agnieszka Strzalka, PhD is an assistant proffessor at the Pedagogical University in Cracow, where she teaches Methodology of Teaching FL courses, Sociolinguistics and assists in MA projects. She has lectured in Spain, Portugal, Austria and Turkey. As a teacher of general and Business English she has been active since 1993. Her research interests include intercultural communication, affect in language learning and teaching and adult education. 